Pre-print version

Full paper:

Staksrud, E. (2019). Top ten types of informed consent your supervisor never told you about. Journal of Children and Media, 13(4), 490-493. doi:10.1080/17482798.2019.166929

\title{
Top ten types of informed consent your supervisor never told you about
}

In the textbook I used as a student, the recruitment of informants is presented as an easy breezy task. While the development of questionnaires and the integration of theory and analysis fill long chapters, the recruitment of informants is more of a statement, rather than a challenge: "Recruit your informants". Period. There are also a few helpful suggestions of where you can find them, including the "if-all-else-fails-there-is-always-the-snowballsampling" advice.

Every time I think back to this section I get the urge to scream and pull my hair out.

Why? Because, when you have spent a substantial amount of your professional life trying to recruit children and youth for research, you gain some experience and knowledge that is never found in your regular textbook. We might call it the dirtier, messier side of research. The "not so good practice". The part where you struggle to get the informants to care, participate or even listen to you. The part where you feel more like an annoying telephone sales representative than a professional wanting to "do good" through research.

The part I have found especially challenging - and also fascinating - is ensuring that your informants provide a fully informed and freely given consent. The "fully informed" (when is someone really "fully" informed? How do we measure this?) and "freely given" (how far can I go trying to persuade them - given that my research is very important?) poses an undercommunicated challenge.

Of course, for an informant, any reason to decline or withdraw participation is a legitimate reason. However, some reasons can be averted or prevented, increasing your chance of getting the data that you need for your research. In order to be most successful, it might be good to know of some core pitfalls, that you may plummet into when trying to ensure a properly informed consent from your young participants. Here are my top ten most challenging examples (some experienced, some observed) related to informed consent - in ascending order by frustration.

No. 10 - the "we are too cool for this" consent

When you try to recruit in schools, explaining the rules of consent and the right to say no, and the coolest opinion-leader type of guy or girl in the class interrupts and states "I am not going to waste my time on this". Chances are high that his or her following by default will be substantially larger than yours, and you are left with a handful of potential informants, rather than the full school class you expected and needed. 


\section{No. 9 - the "I changed my mind (and it is my kid)" consent}

When you collect informed consent from both the parent and the child, with the understanding that the child's answers will remain anonymous, also to the parent, and after collecting the data the parents change their minds, demanding to see what their children have answered, "to check up on them".

No. 8 - the "get out of math class" consent

When collecting in schools, and the students realize that if they say yes to participate, they do not have to go to regular class, seeing the participation more as a break than an incentive to actually do something (like what you need them to do).

No. 7 - the "social pressure" consent

When the grouping of the informants and your method of collecting data creates such a social pressure that it is virtually impossible for them to ask to be excused, without creating social stigma. It might increase the number of informants, but they are not motivated informants; they are more likely to lie in their answers, and it is unethical, as the consent is not freely given.

No. 6 - the "incentive" consent

When the incentive offered for participation in the survey (such as money or gift certificate) is of such importance to the family that the parent commands the child to participate, making voluntary participation and freely given consent impossible to secure from the child itself.

No. 5 - the "do not be selfish" consent

Beneficence is a key value in research and when dealing with informants (see for instance the Belmont Report, 1979), but sometimes this can create undue pressure. Children are often told to be helpful, listen to adults and show respect. The over-emphasis on the beneficence of research participation ("Don't you want to help other children who are bullied/hurt/poor/hungry/do not have a mobile phone?") can create unwarranted pressure for participation.

No. 4 - the "because you owe me" consent

When you have devoted substantial time to setting up for the interview/observation/experiment, perhaps you have even have travelled far, and the informants suddenly change their minds as a more exciting way to spend the afternoon comes along. Then, biting your lip and remembering the "withdraw at any time" rule of research ethics is one of the hardest things to do.

No. 3 - the "because you love me" consent

When you desperately need informants, and at some point contact family, friends, colleagues and students (remembering the textbook "snow-ball-recommendation), pulling on their heartstrings as best as possible. (For media and communication scholars: I have also experienced this with students who themselves are semi-public popular figures, and who ask their fans to participate in their research as informants - "because they love me".) 


\section{No. 2 - the "unicorn" consent}

When the consent form is so full of promises of "having a good time" that it portrays participating in a focus group as attending a fun-filled, pizza-eating party "... with cool adults who really care about what you think" (rather than the boring, but ethically sound, neutral description).

No. 1 - the "over-informed" consent

My overall "favorite" combines the challenges of informed consent, in loco parentis, and the reminder that research ethics, methods and data quality are critically integrated.

Some years ago, when collecting data on digital experiences in five European countries from children (9-16), we recruited schools to participate, well before the data collection would take place. When the data came back, it became clear that for one group of children in one country, the scores on digital literacy, online safety knowledge and overall skills were substantially higher than for other children. Could it be that these children, in this particular part of this country, were so much more clever than their European counterparts? Investigating a bit further it became clear that school principals and school boards that had been asked to participate in the study were so used to public tests (such as the PISA, OECD's programme for international student assessment1) that they felt it was important "that the school did well", seeing the research as a form of testing. Thus, before we came to collect our data, all the students had a three-week intensive "safe use and digital skills course", resulting in a diploma from the school for the students, and biased data to be put in the bin for us.

After two decades with a career in academia, I am still left quite non-plussed. Why is the complicated issue of informed consent so under-communicated to our students, and even between colleagues? And why are we so often left with "this has to be good enough" when assessing the freely given and fully informed quality of the consent? I think the answer is terrifyingly simple. It's about time and money. Get the data, do the analysis, finish the project, secure more funds.

We rarely have - or are allowed to take - the time and resources to recruit yet another class, or travel to yet another town. But, for a number of reasons, not least the public's growing mistrust in research and science, I am quite convinced that the frustrating path of "freely given and fully informed consent" has to be walked and documented, again and again. And student textbooks should give a clearer roadmap of the winding path ahead, rather than presenting it as a wide-open highway.

Notes

1. http://www.oecd.org/pisa/.

\section{Reference}

The National Commission for the Protection of Human Subjects of Biomedical and Behavioral Research. (1979). The belmont report. Ethical principles and guidelines for the protection of human subjects of research. Washington: Department of Health, Education, and Welfare. [Google Scholar] 